\title{
Online teaching and learning: a year later what has changed?
}

\section{Bruno Gonçalves ${ }^{1}$, Vitor Gonçalves ${ }^{2}$}

${ }^{1}$ Instituto Politécnico de Bragança, Portugal, ${ }^{2}$ Research Centre in Basic Education (CIEB), Instituto Politécnico de Bragança, Portugal.

\begin{abstract}
The world is currently experiencing the covid-19 pandemic that has been going on for almost a year and which has transformed the way of carrying out the economic activities that support contemporary societies. The education sector is precisely an example of this abrupt change. The face-to-face teachinglearning process was converted to an online format, so students, teachers, schools and families had to adapt immediately to this transformation. There was no time to provide schools and persons with digital equipment and tools, nor with educational agents for training oriented to the practice of online teaching. Everyone had to do their best, adapting, learning autonomously and with their peers and solving their own problems. This research was developed with the support of the case study methodology in a Portuguese educational institution and aims to understand, through the Dynamic Digital Competence Reference Framework (DigComp), the evolution of students in terms of digital skills in the period of the covid-19 pandemic. The results show that students acquired a set of digital skills that allowed them to participate and interact with stakeholders in the online teaching-learning process. In addition, a set of suggestions is also presented for the acquisition or improvement of other students' skills.
\end{abstract}

Keywords: DigComp; digital skills; online teaching; students; teachinglearning process; technologies. 


\section{Introduction}

Considering that the growth of information and its accessibility through networks is increasingly evident, consequently, it is also a fact that the teaching-learning process will be increasingly linked to learning networks. It is, therefore, essential that all educational agents (students, teachers and school administration) continuously monitor this change and, through it, manage to develop skills and acquire new knowledge, which will allow them to have an effective practice with information and communication technologies. However, any change has associated, directly or indirectly, several obstacles, which prevent it from happening, for example: the fear of failing in front of colleagues, difficulties in using technologies, lack of technical support to solve problems, decrease in social communication skills of individuals, lack of adequate and functional infrastructures, lack of adequate training in the use of technologies, among many others. Despite the obstacles to the integration of technologies in educational environments, it is essential that investment in the training of educational agents in the field of ICT, so that, thus, it is possible to contribute to the improvement of the quality of education, namely, to the improvement of quality teaching-learning process. In literature there is much talk of this theme, but essentially from the perspective of the teacher, but very little in relation to the student. Thus, in the present study, we seek to speak about the digital skills that students must have to operate in online education in times of pandemic. The results show that most of the students acquired new digital skills that allowed them to participate in online teaching. In addition, a set of suggestions is also presented for the acquisition or improvement of other students' skills. It should be noted that these suggestions emerged from the data collection process and, in general, aim to contribute to the digital literacy of educational actors, in particular students of the 21 st century - digital natives. In addition, the importance that these suggestions may have as a contribution to the discussion in the scientific and academic communities.

\section{Online teaching: training in digital skills}

A preliminary analysis of the literature shows that many issues related to online teaching are still not adequately clarified, perhaps due to the constant changes that are felt in education or perhaps because it was never clear. We believe that all these questions deserve to have urgent and clear answers, that are truly useful, duly supported scientifically and, especially, that allow to change the current paradigm of the way and methods of online teaching.

Recent decades show steady growth in online education, with institutions providing more online courses and programs (Allen \& Seaman, 2013, 2016). In fact, we have good examples at the international level of higher education institutions that have been quite successful in implementing online teaching in some of the curricular units they offer, for example: Queen's University, Massachusetts Institute of Technology (MIT), National Taiwan University, 
Stanford University, University of Melbourne, Duke University, The Chinese University of Hong Kong, University of São Paulo, among many others. At national level, not many institutions offer training in online teaching, but the work developed in this area by the Open University (UAb) is recognized. Perhaps because there is still little use of online education, for exemple the Portuguese government has set as goals to train around 3,000 people by 2023 and up to 50,000 people by 2030 in distance learning (Governo de Portugal, 2019). Based on the assumption that these goals are really to be fulfilled, it becomes urgent to address this issue, because: if the number of students in online education increases, more teachers are needed to train these students. Thus, although scholars in the field have identified many techniques, methods, and approaches to aid in the training and support of online instructors (Lackey, 2011), now can be improved to match the objectives defined by the Portuguese government (Governo de Portugal, 2019) and the objectives for sustainable development identified by the United Nations (Assembly, 2015), especially with regard to the substantial increase in the supply of qualified teachers. Although the qualification of teachers can occur at different levels, we believe that it is urgent to qualify these professionals to teach online effectively and efficiently. The urgency in this type of training and qualification has to do with the fact that online education is growing significantly both in the educational field and in the field of training in the workplace. This means that there is an urgent need for a clear commitment to the training of teachers for online teaching, as it is only with this training that it is then possible to train and prepare students for this practice.

The urgency of training teachers and students in digital skills for the 21 st century is foreseen in several European and governmental programs, publications by specialists in the field, documents and agreements. However, due to a set of constraints, many of these formations seem to never be realized or else due to their delay they do not really contribute to the acquisition of digital skills of individuals. Digital Competence is understood as "the set of knowledge, skills, abilities, strategies and attitudes necessary to use digital technologies and media" (Commission, 2018). The delay we are referring to has to do with the difficulty in keeping up with the growth of technologies in the market and with the implementation of these training actions for citizens in general and for students and teachers in particular. In addition to the increase in the supply of qualified teachers foreseen in the "Sustainable Development Goals of the 2030" (Assembly, 2015), Portugal launches the Dynamic Digital Competence Reference Framework (INCoDe.2030, 2019), an instrument for assessing the digital skills of the population. This document is based on the European Digital Skills Framework for Citizens (Carretero et al., 2017) and has three objectives: to support the definition of policies and strategies; design education programs; and evaluate and certify competences, either by self-diagnosis or by certifying entities.

Considering the importance of the Dynamic Digital Competence Reference Framework (DigComp) (INCoDe.2030, 2019) for citizens' digital literacy, the following are the five 
competencies that support this model: Information literacy, Communication and citizenship, Content creation, Security and privacy, and Development of solutions. As part of the European Commission's DigComp initiative, the European Digital Competence Framework for Educators - DigCompEdu, has just been launched, in Portuguese (Lucas \& Moreira, 2018).

\section{Methodology}

This research was developed with the support of the case study methodology in a Portuguese educational institution and aims to understand, through the Dynamic Digital Competence Reference Framework (DigComp), the evolution of students in terms of digital skills in the period of the covid-19 pandemic. For this we want to identify the digital skills of students at the beginning of the covid-19 pandemic and the skills acquired after a year in the context of online education. Comparing the results obtained it will be possible to understand the evolution of students regarding the acquisition of digital skills in online education.

It is important to note that the option for the case study methodology had to do with the fact of explaining a situation and describing an object or phenomenon: "It is an investigation that is assumed to be particularistic, that is, that deliberately looks at a specific situation that is supposed to be unique or special" (Ponte, 2006, p.2), in this specific case, the online teachinglearning process at a school in Portugal.

The educational institution has a total of 147 students, among them, 123 (83.67\%) are female and $24(16.32 \%)$ are male. The percentage of female individuals is very high when compared to the male gender. These results may have to do with the fact that the courses offered by this school - health and social sectors - are more conducive to the participation/attendance of female individuals.

To develop the research three data instruments are used that seem to be absolutely essential: the questionnaire survey, the semi-structured interview and the participant observation. The questionnaire survey was used in two phases: the first, at the beginning of the pandemic (in March 2020) to determine students' initial digital skills; the second phase for the application of the survey was in February 2021, also with the objective of identifying digital skills - one year after the beginning of the pandemic. Both inquiries were sent to the institutional email to all students at the school. The questionnaire survey answered $78.94 \%$ of the female gender and the rest of the male gender (17.89\%). In order to complement the data from the questionnaire survey, a number of students were asked to participate in a semi-structured interview. In the semi-structured interview $66.66 \%$ of the female gender participated and the rest of the male gender (33.33\%). The questionnaire survey was developed with support at DigComp (INCoDe.2030, 2019), namely, through the five competencies (information literacy, communication and citizenship, content creation, security and privacy and 
development of solutions), the proficiency levels and their descriptors. In order to ensure uniformity, the script for the semi-structured interview was also supported by the DigComp board (INCoDe.2030, 2019). Participant observation (investigator's diary) took place during the e-learning period and was used to identify and understand students' digital skills in a virtual context. The information collected was essential to articulate with the data from the questionnaire survey and semi-structured interviews.

It is important to mention that, in the data triangulation process, namely through the semistructured interview and the questionnaire survey, it was possible to find a set of suggestions that can contribute to the improvement and acquisition of students' digital skills. These suggestions emerged through questions to students and categories resulting from the data analysis process.

All data from participant observation (investigator's diary), semi-structured interview and questionnaire surveys submitted to students were properly analyzed in Microsoft Excel through a careful and rigorous analysis.

\section{Search results}

This section presents the results obtained with the development of this study that focus on the digital skills of students at the beginning of the pandemic and the skills acquired after a year in the context of online education. This presentation is based in the Dynamic digital competence reference framework, in which, for each area of competence, a list of competencies are shown. Four levels of proficiency are also listed, presenting examples of use that integrate knowledge, skills and attitudes. In the following two sections we present briefly the digital skills of students in the initial phase of online education (in March 2020) and in the final phase (in February 2021).

\subsection{Digital skills of students at the beginning of the covid-19}

Below are the data for each of the areas of digital competence held by students before the pandemic.

- Information literacy: (1) identify an information search engine; navigate in digital environments in order to obtain necessary information; (2) Recognize useful and appropriate information and data, obtained in digital environments; (3) Recognize the procedures associated with organizing, storing and retrieving data in digital environments.

- Communication and citizenship: (1) Identify and use simple means of communication appropriate for a given context; Identify and use digital technologies to interact with others; (2) Identify appropriate digital technologies to share data, information and digital content;

(3) There is no competence in this area; (4) Identify and use digital tools and technologies 
for collaborative processes; (5) Identify appropriate standards of behavior when using digital technologies and when interacting in digital environments; (6) There is no competence in this area.

- Content creation: (1) Identify programs / applications that make it possible to create digital files; (2) There is no competence in this area; (3) There is no competence in this area.

- Security and privacy: (1) Identify risks and threats in digital environments; (2) Identify risks and threats in the use and sharing of personal information; (3) There is no competence in this area; (4) There is no competence in this area.

- Development of solutions: (1) Identify simple technical problems when operating devices and using digital environments; (2) Identify needs; (3) There is no competence in this area; (4) There is no competence in this area.

The low level of skills or their total absence can be justified by the limitations mentioned by the students in the interview, which were later confirmed by the researcher as an observer, for example: Lack of access to digital (hardware / software); Lack of access to the network outside the school; Limited user skills, due to the lack of contact with ICT; Absence of practice-oriented training with technologies; Family and social environment inhibiting the practice with technologies.

\subsection{The skills acquired after a year in the context of online education}

The data for the areas of digital competence held by students after the pandemic:

- Information literacy: (1) Navigate digital environments in order to obtain the necessary information; (2) There is no competence in this area; (3) Identify appropriate tools for organizing, storing and retrieving data in digital environments; Choose documents of different formats, organizing them in custom folders; Apply appropriate tools for organizing, storing and retrieving data.

- Communication and citizenship: (1) Indicate and use at least one digital technology to interact appropriately; (2) Distinguish appropriate digital technologies for sharing data, information and digital content; (3) Recognize the need to respect digital accessibility standards; (4) There is no competence in this area; (5) Recognize aspects of cultural and generational diversity to be taken into account in digital environments; (6) Identify a digital identity and learn about ways to protect my reputation; Recognize data I produce through digital tools, environments or services; Recognize the difficulty of eliminating my footprint.

- Content creation: (1) Recognize the format of a digital file; Create simple content using specific programs or applications; Distinguish different digital media that allow me to express myself through the creation of digital content; (2) Identify the programs / applications that 
can be used to modify or integrate new content and information, in digital files, giving rise to other new and original items; (3) There is no competence in this area.

- Security and privacy: (1) Identify ways to protect my devices and digital content; Follow pre-defined safety and protection measures; Follow ways to respect reliability and privacy; (2) Recognize personal information that can identify me or that can lead to the identification of others; (3) Identify digital technologies for social well-being and inclusion;

Recognize the importance of ergonomics in the use of digital technologies; Identify risks and threats from the use of digital technologies for health and physical and psychological wellbeing; (4) Identify the environmental impacts resulting from digital technologies and their use; Follow ways of protecting the environment.

- Development of solutions: (1) Identify simple solutions to solve them; (2) Recognize simple digital tools and possible technological responses to solve them; Identify simple ways to adjust and customize digital environments to personal needs; (3) There is no competence in this area; (4) There is no competence in this area.

There is a general evolution of students regarding the acquisition of digital skills in an online context, however, they do not seem to be statistically significant. There are actually a number of students who manage to reach DigComp's intermediate proficiency level, however, most remain at the basic level, showing that the evolution is very low.

\subsection{Suggestions for the acquisition or improvement of students' digital skills}

From the triangulation process of the data collection instruments, particularly the semistructured interview and participant observation, a set of suggestions emerged that can contribute to the acquisition or improvement of students' digital skills:

- Use the latest, appealing and intuitive technologies that encourage students to participate and actively collaborate in online classes. It is essential that teachers choose the most appropriate technologies for each learning context;

- Train students to acquire digital skills. These trainings can, eventually, occur before the beginning of online classes, thus providing students with greater digital dexterity during a module, discipline or course;

- Provide teachers with digital skills, through training actions inserted in their professional development - continuous teacher training;

- Adopt, in the context of online teaching, synchronous tools that enable students to communicate, interact and collaborate in real time;

- Use gamification to motivate behaviors and make complex content into more accessible materials, facilitating the learning processes; 
- Promote the constant updating of the content of the Subject of Information and Communication Technologies (ICT) and other that involve digital tools;

- Provide educational institutions with recent and useful technologies for learning and make technological equipment available to students free of charge.

\section{Conclusions}

In this study we identified the digital skills of students at the beginning of the covid-19 pandemic and the skills acquired after a year in the context of online education. We can say, beginning the pandemic, students had a very low level of digital skills - the largest group held basic DigComp skills. The remaining students were practically unaware of digital tools, their domain or their use. These questions seem to be related to a set of conditions that inhibit students' practice with digital technologies. During the period of online teaching, students were able to obtain a set of digital skills, however, they only managed to reach at most the intermediate proficiency level, staying almost always at the basic level. This means that during this period the students limited themselves to using technologies absolutely essential for carrying out the activities and tasks of the subjects in an online context. In general, students did not feel motivated and interested in investing time in the acquisition of more advanced digital skills, remaining only with the basic skills in the user's perspective.

Finally, the results identify a set of suggestions that can contribute to the acquisition or improvement of students' digital skills. These suggestions are related to the use of the latest technologies, the promotion of training actions for students, the adoption of tools that enable collaboration and the use of gamification to motivate behaviors and make complex content into more accessible materials. In addition, the value that these suggestions may have as a contribution to discussion in the scientific and academic communities.

\section{Acknowledgment}

This work has been supported by FCT - Fundação para a Ciência e Tecnologia within the Project Scope: UIDB/05777/2020.

\section{References}

Allen, I. E., \& Seaman, J. (2013). Changing course: Ten years of tracking online education in the United States. ERIC.

Allen, I. E., \& Seaman, J. (2016). Online Report Card: Tracking Online Education in the United States. ERIC.

Assembly, U. N. G. (2015). Resolution adopted by the General Assembly on 25 September 2015. Washington: United Nations. 
Carretero, S., Vuorikari, R., \& Punie, Y. (2017). DigComp 2.1: The Digital Competence Framework for Citizens with eight proficiency levels and examples of use. Joint Research Centre (Seville site).

Commission, E. (2018). Proposal for a council recommendation on key competences for lifelong learning. Education and Training: Key Competences.

Governo de Portugal. (2019). Um “contrato para a Legislatura” com o Ensino Superior para 2020 - 2023, orientado para estimular a convergência de Portugal com a Europa até 2030.

INCoDe.2030. (2019). Quadro Dinâmico de Referência de Competência Digital (QDRCD).

Lackey, K. (2011). Faculty development: An analysis of current and effective training strategies for preparing faculty to teach online. Online Journal of Distance Learning Administration, 14(4), 8.

Lucas, M. \&, Moreira, A. (2018). DigCompEdu: Quadro Europeu de Competência Digital para Educadores. Aveiro: UA Editora.

Ponte, J. P. da. (2006). Estudos de caso em educação matemática. Bolema, 105-132. 